\title{
Evaluation of the best method to assess antibiotic potentiation by phytochemicals against Staphylococcus aureus
}

\author{
Ana Cristina Abreu ${ }^{a}$, Sofia C. Serra ${ }^{b, c}$, Anabela Borges ${ }^{a, d}$, Maria José Saavedra ${ }^{d}$, \\ António J. Salgado ${ }^{\mathrm{b}, \mathrm{c}}$, Manuel Simões ${ }^{\mathrm{a}, *}$ \\ a LEPABE, Department of Chemical Engineering, Faculty of Engineering, University of Porto, Rua Dr Roberto Frias, s/n, 4200-465 Porto, Portugal \\ ${ }^{\mathrm{b}}$ Life and Health Sciences Research Institute (ICVS), School of Health Sciences,University of Minho, Campus de Gualtar, 4710-057 Braga, Portugal \\ ' ICVS/3B's, PT Government Associate Laboratory, Braga/Guimarães, Portugal

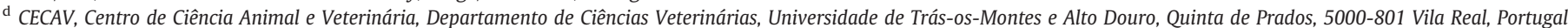

\section{A R T I C L E I N F O}

\section{Article history:}

Received 10 October 2013

Received in revised form 18 February 2014

Accepted 2 March 2014

Available online 12 March 2014

\section{Keywords:}

Alkaloids

Co-therapy

Efflux pump

Potentiation

Resistance-modifying agents

\begin{abstract}
A B S T R A C T
The increasing occurrence of bacterial resistance to antibiotics has now reached a critical level. Finding antibiotic coadjuvants capable to inhibit the bacterial resistance mechanisms would be a valuable mid-term solution, until new classes of antibiotics are discovered. Selected plant alkaloids were combined with 5 antibiotics against 10 Staphylococcus aureus strains, including strains expressing distinct efflux pumps and methicillin-resistant $S$. aureus strains. The efficacy of each combination was assessed using the microdilution checkerboard, time-kill, Etest, and disc diffusion methods. The cytotoxicity of the alkaloids was evaluated in a mouse fibroblast cell line. Potentiation was obtained in $6 \%$ of all 190 combinations, especially with the combination of: ciprofloxacin with reserpine (RES), pyrrolidine (PYR), and quinine (QUIN); tetracycline with RES; and erythromycin with PYR. The highest cytotoxicity values were found for QUIN (half maximal inhibitory concentration $\left.\left[\mathrm{IC}_{50}\right]=25 \pm 2.2 \mathrm{mg} / \mathrm{L}\right)$ and theophylline $\left(\mathrm{IC}_{50}=100 \pm 4.7 \mathrm{mg} / \mathrm{L}\right)$.
\end{abstract}

(C) 2014 Elsevier Inc. All rights reserved.

\section{Introduction}

The evolution of bacterial resistance increased over the last years, and given the difficulty of new drug discovery by the traditional methods, new strategies are urgently needed. The use of paired and even triple combinations of antimicrobial drugs with positive in vitro interactions has become increasingly important in clinical applications. The combinatorial therapy has also been a common practice in order to prevent the emergence and widespread of multi-drugresistant (MDR) infections (Sopirala et al., 2010). Indeed, the biological system is less able to compensate for the action of 2 or more drugs simultaneously (Zimmermann et al., 2007). Also, the cost of developing a new antimicrobial versus the cost of finding a combination between known ones is an easy justification for research into drug potentiation (Lambert et al., 2003).

While several bioactive compounds have a significant antimicrobial activity, other compounds have been found to be synergistic enhancers of antibiotics, despite they may not have any antimicrobial properties alone (Abreu et al., 2012b). The modes of action underlying the synergistic activity of these antibiotic adjuvants can be diverse. Two important mechanisms include the serial or orthogonal inhibition of vital physiological pathways or the dispersion of a biofilm to

\footnotetext{
* Corresponding author. Tel.: +351-225081654; fax: +351-225081449.

E-mail address: mvs@fe.up.pt (M. Simões).
}

planktonic cells, resulting in an increased susceptibility to antibiotics (Kalan and Wright, 2011). Also, several antibiotic adjuvants have been evaluated for their action as resistance-modifying agents (RMAs) (Hemaiswarya et al., 2008), i.e., compounds that can modify or inhibit the bacterial mechanisms of resistance, so that antibiotics can efficiently kill the resistant bacteria. Several RMAs were already described (Chan et al., 2011; Gibbons et al., 2003; Khan et al., 2006; Roccaro et al., 2004; Schmitz et al., 1998; Yam et al., 1998). Efflux pump inhibitors (EPIs) are important examples of RMAs since they can prevent the extrusion of an antibiotic to the exterior of the cell and thus allow the antibiotic to act efficiently against bacteria. If such compounds were clinically approved, many inefficient and old antibiotics (for which resistance mechanisms are already disseminated) could be recycled. Therefore, many of the current problems on the lack of new antibiotics and new classes of antimicrobials would be possible to solve.

It is unquestionable that natural compounds have been a major source of new bioactive agents. In fact, natural compounds were already "prescreened" over millions of years ago by natural selection, which puts them ahead in the race for the discovery of new antimicrobials. Plants have been traditionally used for centuries to treat human diseases and inhibit microbial growth. They are important sources of a wide variety of secondary metabolites such as alkaloids, isothiocyanates, peptides, phenolics, polyacetilenes, and terpenoids, which have been well-established to possess 
antimicrobial properties (Phatthalung et al., 2012). Alkaloids are heterocyclic nitrogen compounds (Cowan, 1999). There is an excellent rationale that plant alkaloids should possess antibacterial activity, particularly given the number of cytotoxic drugs and templates from this source (Gibbons, 2004).

The objective of this work was to determine whether several alkaloids (caffeine [CAF], reserpine [RES], pyrrolidine [PYR], theophylline [THEO], and quinine [QUIN], Fig. 1) were able to improve the activity of common antibiotics belonging to several classes (ampicillin [AMP] and oxacillin [OXA] - $\beta$-lactams; ciprofloxacin [CIP] fluoroquinolone; erythromycin [ERY] - macrolide; and tetracycline [TET]). Several resistant strains of Staphylococcus aureus were used. S. aureus and, specifically, MRSA strains are important pathogens in clinical settings, responsible for a high level of hospital-acquired infections (Oluwatuyi et al., 2004), due to their great capacity of acquiring resistance genes. The methods for detecting potentiation used in this work were the broth microdilution checkerboard, timekill assay, Etest, and the disc diffusion method (DDM). A comparison of the results of potentiation given by these 4 methods was evaluated.

\section{Materials and methods}

\subsection{Bacterial strains}

Three clinical MRSA (MJMC001, MJMC002, MJMC004) and 3 clinical MSSA (MJMC003, MJMC009, MJMC010) were isolated from patients with diabetic feet at the Centro Hospitalar de Trás-os-Montes e Alto Douro, EPE (Portugal). S. aureus SA1199B, which overexpresses the NorA MDR efflux pump, S. aureus RN4220, which contains plasmid pU5054 (that carries the gene encoding the MsrA macrolide efflux protein), and S. aureus XU212, which possesses the TetK efflux pump and is also an MRSA strain, were kindly provided by S. Gibbons (University College London, UCL) (Gibbons and Udo, 2000; Gibbons et al., 2003; Oluwatuyi et al., 2004; Smith et al., 2007). The collection strain S. aureus CECT 976, already used as model microorganism for antimicrobial tests with phytochemical compounds(Abreu et al., 2012a; Saavedra et al., 2010; Simões et al., 2008), was included as a quality control strain. Prior to use, each strain at $-80{ }^{\circ} \mathrm{C}$ was transferred onto Mueller-Hinton (MH; Merck, Darmstadt, Germany) agar plate, grown overnight, and inoculated into $\mathrm{MH}$ broth at $37{ }^{\circ} \mathrm{C}$ and under agitation (150 rpm).

\subsection{Antibiotics and alkaloids}

AMP, CIP, ERY, OXA, and TET were obtained from Sigma (Portugal) and prepared according to the manufacturer recommendations. CAF, RES, PYR, THEO, and QUIN were purchased from Sigma and the stock solutions were prepared in dimethyl sulfoxide (DMSO; Sigma, Sintra, Portugal). Etest strips of the antibiotics (AB Biodisk, Solna, Sweden) were obtained from Izasa (Portugal, Barcelona, Spain).

\subsection{Antibacterial susceptibility testing}

The MIC of each agent was determined by microdilution techniques according to the Clinical and Laboratory Standards Institute (CLSI) guidelines (NCCLS/CLSI, 2003). For S. aureus SA1199B, RN4220, and XU212, only CIP, ERY, and TET were tested, respectively. Bacteria $\left(\sim 10^{6} \mathrm{CFU} / \mathrm{mL}\right)$ were inoculated into $\mathrm{MH}$ broth and dispensed at $200 \mu \mathrm{L} /$ well in 96 -well microtiter plates, along with 2 -fold dilutions of the compounds to test. Several intermediate concentrations were also prepared in order to minimize the errors in MIC determination. MIC was defined as the lowest concentration of the antimicrobial compound that inhibited bacterial growth after $24 \mathrm{~h}$ of incubation at $37^{\circ} \mathrm{C}$. The bacterial growth was determined at 600 nm using a microplate reader (Spectramax M2e; Molecular Devices, Inc., Sunnyvale, USA). Three independent experiments were performed for each compound. The highest concentration of DMSO remaining after dilution $(10 \%(\mathrm{v} / \mathrm{v}))$ caused no inhibition of bacterial growth (data not shown).

\subsection{Checkerboard microdilution assay}

Checkerboard testing was performed in 96-well microtiter plates in triplicate according to Chan et al. (2011) with some modifications. After an overnight incubation into $\mathrm{MH}$ broth at $37{ }^{\circ} \mathrm{C}$, bacterial cultures were adjusted in fresh broth to approximately $10^{6} \mathrm{CFU} / \mathrm{mL}$<smiles>Cn1c(=O)c2c(ncn2C)n(C)c1=O</smiles>

Caffeine

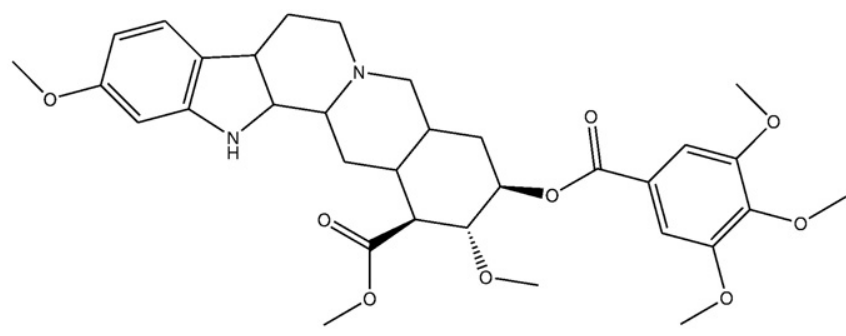

Reserpine<smiles>C1CCNC1</smiles>

Pyrrolidine<smiles>Cn1c(=O)c2[nH]cnc2n(C)c1=O</smiles>

Theophylline

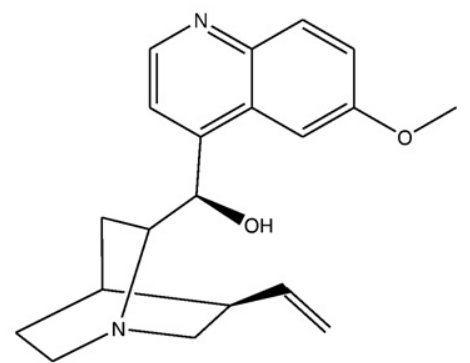

Quinine

Fig. 1. Chemical structures of the alkaloids used in this study. 
Bacterial suspensions were added to each well along with the antibiotics and alkaloids (in a total volume of $200 \mu \mathrm{L}$ ) in different concentrations so that each well contains the same amount of the antibiotic, which is being 2-fold diluted along the $\mathrm{x}$ axis (rows), and the same amount of the alkaloid being diluted on the $y$ axis (columns). Also, concentrations between the 2-fold dilutions range were prepared. The antimicrobial solutions did not exceed $10 \%(\mathrm{v} / \mathrm{v})$ of the well. The concentration of each antibiotic tested ranged from 1/64 to $2 \times$ MIC. The alkaloids were tested at several concentrations ranging from 10 to $1000 \mathrm{mg} / \mathrm{L}$, depending on the strain. Negative growth controls were performed in a separate microtiter plate by mixing sterile medium, without bacteria, with the alkaloids. Readings were determined spectrophotometrically at $600 \mathrm{~nm}$.

\subsection{Etest}

Etest was only directed for the antibiotics, which achieved good combinatorial results on the checkerboard and the disc diffusion methods. This method was performed according to the manufacturer's instructions. Each alkaloid was added to $\mathrm{MH}$ agar (after autoclaved and cooled) yielding the final concentration desired, which was chosen according to the checkerboard results. Then, the medium was poured into $90 \mathrm{~mm}$ Petri dishes to give a uniform depth of approximately $4 \mathrm{~mm}(\sim 20 \mathrm{~mL})$. The bacterial suspensions were adjusted to 0.5 McFarland standards and seeded over hardened $\mathrm{MH}$ agar Petri dishes using a sterilized cotton swab and allowed to set (for 10-15 min). Antibiotic Etest strips were applied in duplicate on the $\mathrm{MH}$ agar plates. As control, the antibiotic strips were applied on simple $\mathrm{MH}$ agar plates (without the alkaloid). Plates were incubated for $24 \mathrm{~h}$ at $37^{\circ} \mathrm{C}$. The MICs were read on plates with the combination of the 2 agents and on antibiotic control plates.

\subsection{Disc diffusion method}

This was a modification from the Kirby-Bauer method, and it was already applied in other studies (Abreu et al., 2012a; Saavedra et al., 2010). The bacterial inoculum and the MH agar plates were prepared in the same way of that described for Etest. The concentration of the alkaloids on the agar was chosen according to the checkerboard results. Sterile blank discs (6-mm diameter; Oxoid, Oeiras, Portugal) were placed on the agar plate seeded with the respective bacteria. A volume of $15 \mu \mathrm{L}$ of each antibiotic prepared according to the CLSI guidelines (AMP - $10 \mu \mathrm{g} / \mathrm{disc}$; CIP - $5 \mu \mathrm{g} / \mathrm{disc}$; ERY - $15 \mu \mathrm{g} / \mathrm{disc}$; TET $30 \mu \mathrm{g} / \mathrm{disc}$; and OXA - $1 \mu \mathrm{g} / \mathrm{disc}$ ) (CLSI, 2003) was added to the blank discs. Discs of antibiotics on simple MH agar plates (without the alkaloid) were used as positive controls, and discs impregnated with DMSO were used as negative controls. The plates were incubated at $37^{\circ} \mathrm{C}$ for $24 \mathrm{~h}$. After incubation, each inhibition zone diameter (IZD) was recorded and analyzed according to CLSI guidelines (CLSI, 2003). No inhibition zone was obtained with DMSO (data not shown). All tests were performed in triplicate, and the antibacterial activity was expressed as the mean of IZD (in $\mathrm{mm}$ ).

\subsection{Time-kill assay}

Time-kill studies were performed according to Roccaro et al. (2004) with some modifications. This method was only performed with strains SA1199B, RN4220, and XU212. Overnight cultures were diluted with $\mathrm{MH}$ broth to a starting inoculum of $10^{6} \mathrm{CFU} / \mathrm{mL}$. Each antibiotic was tested at MIC, $1 / 2 \times$ MIC and $1 / 4 \times$ MIC. The concentration of the alkaloid was chosen according to the checkerboard results. The combinations were added to sterilized $50 \mathrm{~mL}$ polystyrene capped tubes and inoculated with each isolate in a total volume of $10 \mathrm{~mL}$. The antimicrobial combinations did not exceed $10 \%(\mathrm{v} / \mathrm{v})$ of the final volume. Controls were performed with each compound separately. The tubes were agitated in an orbital shaker $(150 \mathrm{rpm})$ at $37^{\circ} \mathrm{C}$ for 24 h. CFU counts in MH agar were performed after $0,4,8$, and $24 \mathrm{~h}$ of the beginning of the incubation. Before CFU counts, plates were incubated at $37{ }^{\circ} \mathrm{C}$ for $18-24 \mathrm{~h}$. The limit of detection was $50 \mathrm{CFU} / \mathrm{mL}$.

\subsection{Classification of a combination as negative/indifferent/additive/ potentiation}

Positive interactions that intensify the potency of a bioactive product are generally called potentiation. Additive and synergistic effects are subsets of potentiation involved when this effect is experimentally characterized and quantified. Negative interactions (interferences) occur when certain components of the mixture inhibit full biological activity of pharmacologically-active compounds by reducing their stability or bioavailability or by enhancing their metabolism (Lila and Raskin, 2005).

A new approach was developed for interactions between compounds that have no antimicrobial activity but that can potentiate antimicrobials. This approach is based on some synergistic definitions applied for combinations involving 2 antimicrobials using checkerboard (Mackay et al., 2000; Rand et al., 1996), Etest(Cantón et al., 2005; Lewis et al., 2002; Sopirala et al., 2010) and time-kill assay (Eliopoulos and Eliopoulos, 1988; NCCLS/CLSI, 1999). Table 1 presents the scheme proposed to classify an interaction as negative, indifferent, additive, or potentiation.

In order to propose a classification scheme for the interactions obtained with DDM, simple linear regressions were performed in order to define linear functions correlating the data from checkerboard and Etest to the DDM results (Fig. 2). The Etest and checkerboard variables were linearized by logarithmic conversions. The population $(\mathrm{n})$ used for this correlation included not only data from this study but also other synergistic data obtained in parallel studies between these antibiotics tested and other plant compounds. The strength of the linear association between pairs of variables was determined by coefficients of determination $(R$ square). According to the scheme proposed by Nicodemo et al. (2004), a strong correlation was found between Etest and DDM $(R$ square $=77.4 \% ; P<0.05 ; \mathrm{n}=240)$ and between checkerboard and DDM $(R$-square $=71.4 \%, P<0.05 ; \mathrm{n}=380)$.

The classification of each combination was compared between methods. Agreement between methods was defined as all methods

Table 1

Characterization of the effect promoted by a phytochemical in the activity of 1 antimicrobial agent.

\begin{tabular}{|c|c|c|c|c|}
\hline Interaction & Checkerboard & Etest & DDM & Time-kill assay \\
\hline Potentiation & $\mathrm{MIC}_{\mathrm{a}}$ reduction $>4$-fold dilutions & $\mathrm{MIC}_{\mathrm{a}}$ reduction $>3$-fold dilutions & $\left(\mathrm{IZD}_{\mathrm{a}+\mathrm{p}}-\mathrm{IZD}_{\mathrm{a}}\right) \geq 6 \mathrm{~mm}$ & $\begin{array}{l}\geq 2 \log _{10} \text { decrease in } \mathrm{CFU} / \mathrm{mL} \text { of } \\
\text { the antibiotic }\end{array}$ \\
\hline Additive & $\begin{array}{l}\mathrm{MIC}_{\mathrm{a}} \text { reduction } \geq 2 \text {-fold and } \\
<4 \text {-fold dilutions }\end{array}$ & $\begin{array}{l}\mathrm{MIC}_{\mathrm{a}} \text { reduction } \geq 2 \text {-fold and } \\
<3 \text {-fold dilutions }\end{array}$ & $4 \leq\left(\mathrm{IZD}_{\mathrm{a}+\mathrm{p}}-\mathrm{IZD}_{\mathrm{a}}\right)<6 \mathrm{~mm}$ & $\begin{array}{l}\log _{10} \text { decrease } \geq 1 \text { and }<2 \text { in } C F U / m L \\
\text { of the antibiotic }\end{array}$ \\
\hline Negative & $\mathrm{MIC}_{\mathrm{a}}$ increase $>4$-fold dilutions & $\mathrm{MIC}_{\mathrm{a}}$ increase $\geq 3$-fold dilutions & $\left(\operatorname{IZD}_{\mathrm{a}}-\mathrm{IZD}_{\mathrm{a}+\mathrm{p}}\right) \geq 6 \mathrm{~mm}$ & $\begin{array}{l}\geq 2 \text { - } \log _{10} \text { increase in } \mathrm{CFU} / \mathrm{mL} \text { of } \\
\text { the antibiotic }\end{array}$ \\
\hline
\end{tabular}

Indifferent interactions are considered between the limits proposed for additive and negative interactions. $\mathrm{a}=$ antibiotic; $\mathrm{p}=$ phytochemical. 

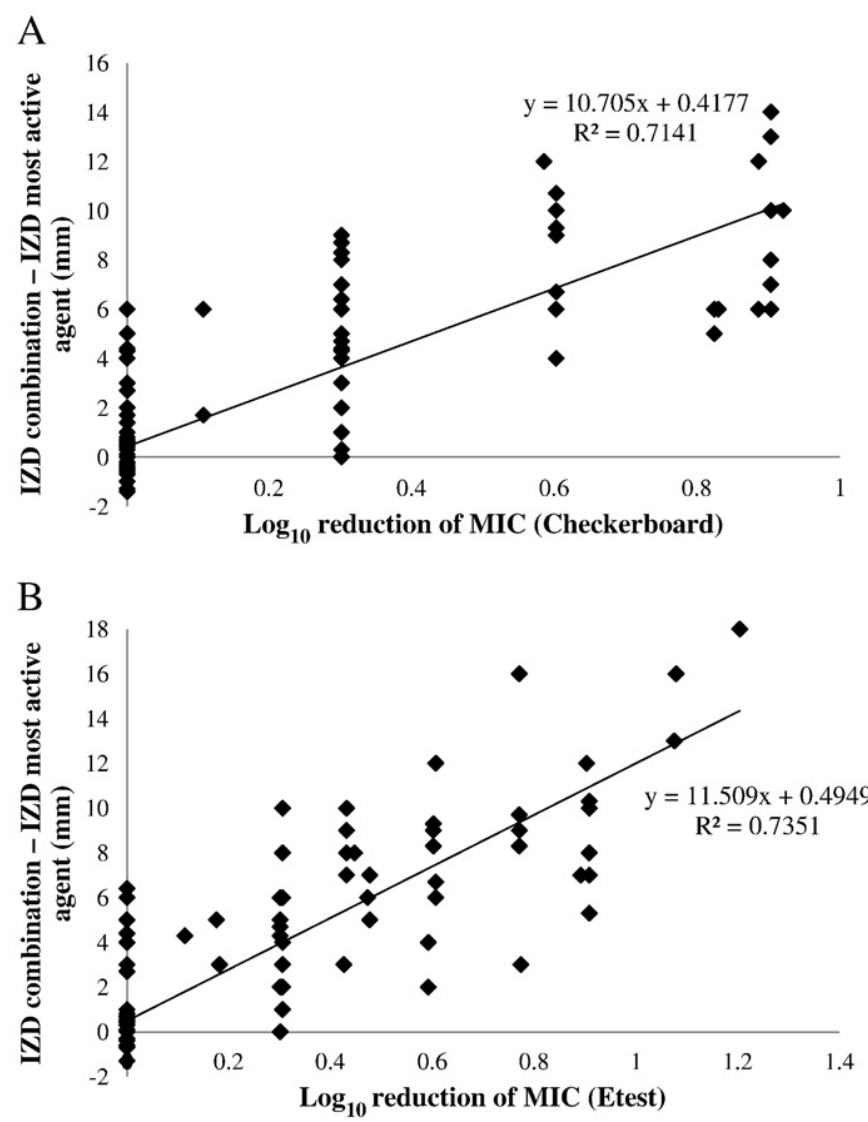

Fig. 2. Correlation between the DDM results (IZD combination - IZD most active agent) and the MIC reductions given by checkerboard (A) and by Etest (B).

having the same interpretative category; minor disagreement, as only 1 method displaying disagreement results; and major disagreement was defined when 2 or more methods display disagreement results.

\subsection{Cytotoxicity tests}

The cytotoxicity of the alkaloids was evaluated according to ISO/ EN 10993 (part 5) guidelines with some modifications (ISO document 10993, 1992). L929 cells (ATCC CCL 1), derived from an immortalized mouse lung fibroblast cell line and routinely used in in vitro cytotoxicity assessments, were used. Cells were grown in $175 \mathrm{~cm}^{2}$ culture flasks using Dulbecco's modified eagle medium (DMEM; Sigma) supplemented with $1 \%$ of penicillin/streptomycin solution (Sigma) and 10\% of fetal bovine serum (FBS; Biochrome, Matosinhos, Portugal). The flasks were incubated at $37{ }^{\circ} \mathrm{C}$ for $72 \mathrm{~h}$ in a $95 \%$ air $5 \%$ $\mathrm{CO}_{2}$ atmosphere with $100 \%$ humidity. Twenty-four hours before the cytotoxicity tests starts, cells were trypsinised, seeded in 96-well microtiter plates at a concentration of $1 \times 10^{4}$ cells per well, and left to adhere at $37{ }^{\circ} \mathrm{C}$ in a $95 \%$ air $5 \% \mathrm{CO}_{2}$ atmosphere with $100 \%$ humidity. Then, the medium in each well was replaced by $200 \mu \mathrm{L}$ of fresh DMEM with the alkaloids at several concentrations (chosen according to the antimicrobial assays). The alkaloids did not exceed $2 \%$ $(\mathrm{v} / \mathrm{v})$ of the well final volume. The positive control was performed by adding fresh medium without any alkaloid and the negative control by adding DMSO at $2 \%(\mathrm{v} / \mathrm{v})$. Each condition was performed in 5 wells and in triplicate. The plates were incubated for $72 \mathrm{~h}$ (at $37{ }^{\circ} \mathrm{C}$, in a $95 \%$ air $5 \% \mathrm{CO}_{2}$ atmosphere with $100 \%$ humidity). Then, the cell viability was assessed by using the Cell Titer $96 \AA$ One solution Cell proliferation Assay Kit (Promega, Madrid, Spain). This assay involves the bioreduction of the substrate (3-(4,5-dimethylthiazol-2-yl)-5-(3carboxyl-methoxy-phenyl)-2(4-sulfophenyl)-2H tetrazolium) (MTS) into a brown formazan product by NADPH or NADP produced by dehydrogenase enzymes in metabolically active cells (Baran et al., 2004).After incubation, the medium with alkaloids was removed and replaced by $200 \mu \mathrm{L}$ of a mixture of DMEM without FBS and MTS (1:5 ratio) and incubated at the same conditions for $3 \mathrm{~h}$. The optical density (OD) of each well was measured at $490 \mathrm{~nm}$ using a plate reader (Molecular Devices, Sunnyvale, USA). From the dose-response curves obtained, the half maximal inhibitory concentration $\left(\mathrm{IC}_{50}\right)$ values were calculated by probit analysis, according to Sebaugh (2011).

\subsection{Statistical analysis}

For statistical analysis, the in vitro results were analyzed by Student's $t$ test using the statistical program SPSS version 19.0 (Statistical Package for the Social Sciences). Statistical calculations were based on a confidence level $\geq 95 \%(P<0.05)$, which was considered statistically significant. Relatively to the simple linear regressions performed correlating the checkerboard and Etest data to the DDM results, the validation of these linear models was carried out by F-test. All $P$ values reported were 2-tailed, and values lower than 0.05 were considered significant.

\section{Results}

All alkaloids were assessed for antibacterial activity using the broth microdilution technique. Only QUIN had antibacterial activity, with an MIC of $500 \mathrm{mg} / \mathrm{L}$ for S. aureus CECT 976. For the other strains, no MIC was detected for QUIN for the concentrations tested (until $1500 \mathrm{mg} / \mathrm{L}$ ). The other alkaloids had no activity against the strains tested for the same concentrations (data not shown). RES reacted with the $\mathrm{MH}$ broth causing a blank turbidity, which complicated the detection of its MIC. Therefore, colony counts in $\mathrm{MH}$ agar were performed in order to evaluate the growth of the bacteria with the increasing concentrations of RES. No growth reduction was verified.

The MICs of the antibiotics alone and in combination with alkaloids obtained by microdilution technique and Etest are shown in Tables 2 and 3, respectively. The agreement between the MICs (only of the antibiotics) obtained by these 2 methods (within $\pm 1 \log _{2}$ dilutions) was of $75 \%$ for TET, $88 \%$ for ERY, and only $38 \%$ for CIP. The overall level of agreement was $66.7 \%$. The discrepancy results were caused by broth MICs higher than Etest MICs. No increase in the MICs of the antibiotics was obtained in the presence of alkaloids $(P>0.05)$. Table 4 shows the IZDs obtained by the DDM method for each combinatorial case. No IZD was obtained with each alkaloid alone (data not shown). The IZD of each combination was never smaller than that produced by each drug alone $(P>0.05)$.

According to the analysis of MICs and IZDs by the susceptibility breakpoints of the NCCLS/CLSI (2003), the MRSA strains were classified as resistant to AMP, OXA, ERY, and CIP and only susceptible to TET. MSSA strains were classified as susceptible to all antibiotics, with exception of AMP. Broth test, Etest, and DDM showed 95\% agreement on these classifications.

Time-kill assay was only performed for the strains with known efflux pumps (S. aureus SA1199B, XU212, RN4220) since only few concentrations of the drugs can be tested in each assay. Fig. 3 shows the $\log _{10}$ increase or decrease in antibacterial activity obtained for each combination over the single activity of the antibiotic alone. No CFU reduction was observed with the alkaloids alone for the concentrations tested $(P>0.05$, data not shown). The effect of the combination between PYR and CIP (at $1 / 2$ MIC) against $S$. aureus SA1199B caused a $2.4 \log _{10}$ decrease in $\mathrm{CFU} / \mathrm{mL}$ (with an initial inoculum of $6.5 \pm 0.53 \log _{10} \mathrm{CFU} / \mathrm{mL}$ to undetectable levels) after $24 \mathrm{~h}$ when compared with CIP alone. Also, the combination between QUIN and CIP (at $1 / 2$ MIC) caused a $1.3 \log _{10}$ decrease in CFU/mL after the same time. Tetracycline (at $1 / 2 \mathrm{MIC}$ ) combined with RES and QUIN against $S$. aureus XU212 achieved a $\log _{10}$ reduction of 2.8 and 2.0 in 
Table 2

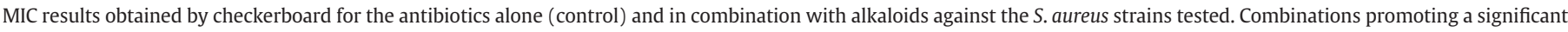
antibiotic MIC reduction $(\mathrm{P}<0.05)$ are in bold.

\begin{tabular}{|c|c|c|c|c|c|c|c|}
\hline \multicolumn{8}{|c|}{ Checkerboard MICs } \\
\hline Isolates & Antib. & Control & CAF & RES & PYR & THEO & QUIN \\
\hline \multirow[t]{5}{*}{ СЕCT 976} & CIP & 1 & 1 & 1 & 1 & 1 & 1 \\
\hline & TET & 0.96 & 0.96 & 0.96 & 0.96 & 0.96 & 0.96 \\
\hline & ERY & 0.24 & 0.24 & 0.24 & $0.06(4.0)$ & 0.24 & 0.24 \\
\hline & AMP & 1.5 & 1.5 & 1.5 & 1.5 & 1.5 & 1.5 \\
\hline & OXA & 0.48 & 0.48 & 0.48 & 0.48 & 0.48 & 0.48 \\
\hline SA1199B & CIP & 128 & 128 & $64(2.0)$ & $64(2.0)$ & 128 & 100 \\
\hline XU212 & TET & 128 & 128 & $32(4.0)$ & 128 & 128 & 100 \\
\hline RN4220 & ERY & 256 & 256 & 256 & $64(4.0)$ & 256 & 256 \\
\hline \multirow[t]{5}{*}{ MRSA MJMC001 } & CIP & 256 & 256 & 256 & 256 & 256 & 256 \\
\hline & TET & 0.5 & 0.5 & 0.5 & 0.5 & 0.5 & $0.25(2.0)$ \\
\hline & ERY & 96 & 96 & 96 & 96 & 96 & 96 \\
\hline & AMP & 64 & 64 & 64 & 64 & 64 & 64 \\
\hline & OXA & 128 & 128 & 128 & 128 & 128 & 128 \\
\hline \multirow[t]{5}{*}{ MRSA MJMC002 } & CIP & 256 & 256 & 256 & 256 & 256 & 256 \\
\hline & TET & 0.5 & 0.5 & $0.25(2.0)$ & 0.5 & 0.5 & $0.25(2.0)$ \\
\hline & ERY & 96 & 96 & 96 & 96 & 96 & 96 \\
\hline & AMP & 64 & 64 & 64 & 64 & 64 & 64 \\
\hline & OXA & 128 & 128 & 128 & 128 & 128 & 128 \\
\hline \multirow[t]{5}{*}{ MRSA MJMC004 } & CIP & 256 & 256 & 256 & 256 & 256 & 256 \\
\hline & TET & 0.5 & 0.5 & 0.5 & 0.5 & 0.5 & 0.5 \\
\hline & ERY & 96 & 96 & 96 & 96 & 96 & 96 \\
\hline & AMP & 64 & 64 & 64 & 64 & 64 & 64 \\
\hline & OXA & 15.6 & 15.6 & 15.6 & 15.6 & 15.6 & 15.6 \\
\hline \multirow[t]{5}{*}{ MSSA MJMC003 } & $\mathrm{CIP}$ & 0.5 & 0.5 & $0.25(2.0)$ & $0.25(2.0)$ & 0.5 & $0.25(2.0)$ \\
\hline & TET & 2 & 2 & 2 & $1(2.0)$ & 2 & $1(2.0)$ \\
\hline & ERY & 0.5 & 0.5 & $0.25(2.0)$ & $0.13(4.0)$ & 0.5 & $0.25(2.0)$ \\
\hline & AMP & 25 & 25 & $3.7(6.8)$ & 25 & 25 & 25 \\
\hline & OXA & 1 & 1 & 1 & 1 & 1 & 1 \\
\hline \multirow[t]{5}{*}{ MSSA MJMC009 } & CIP & 1 & 1 & $0.5(2.0)$ & $0.13(8.0)$ & 1 & $0.25(4.0)$ \\
\hline & TET & 0.5 & 0.5 & $0.06(8.3)$ & $0.25(2.0)$ & 0.5 & $0.06(8.3)$ \\
\hline & ERY & 2 & 2 & 2 & $1(2.0)$ & 2 & $1(2.0)$ \\
\hline & AMP & 10 & 10 & $1.5(6.7)$ & $0.74(13.5)$ & 10 & $1.5(6.7)$ \\
\hline & OXA & 1 & 1 & 1 & 1 & 1 & 1 \\
\hline \multirow[t]{5}{*}{ MSSA MJMC010 } & CIP & 1 & 1 & $0.13(7.7)$ & $0.25(4.0)$ & 1 & 1 \\
\hline & TET & 0.5 & 0.5 & $0.06(8.3)$ & 0.5 & 0.5 & $0.06(8.3)$ \\
\hline & ERY & 0.5 & 0.5 & 0.5 & $0.25(2.0)$ & 0.5 & $0.25(2.0)$ \\
\hline & AMP & 10 & 10 & 10 & 10 & 10 & 10 \\
\hline & OXA & 1 & 1 & 1 & 1 & 1 & 1 \\
\hline
\end{tabular}

MICs ranged between 2-fold dilutions and the highest value was chosen ( $n \geq 3$ ). CAF, PYR, THEO: 500 mg/L; RES, QUIN: 100 mg/L. Fold reductions are given in parentheses.

Table 3

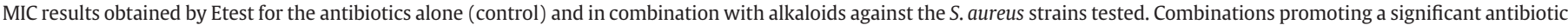
MIC reduction $(\mathrm{P}<0.05)$ are in bold.

\begin{tabular}{|c|c|c|c|c|c|c|c|}
\hline \multicolumn{8}{|l|}{ Etest MICs } \\
\hline Isolates & Antib. & Control & CAF & RES & PYR & THEO & QUIN \\
\hline \multirow[t]{3}{*}{ СЕСТ 976} & CIP & 0.064 & 0.064 & 0.064 & 0.064 & 0.064 & 0.064 \\
\hline & TET & 0.38 & 0.38 & 0.38 & 0.38 & 0.38 & 0.38 \\
\hline & ERY & 0.19 & 0.19 & 0.19 & $0.047(4.0)$ & 0.19 & 0.19 \\
\hline SA1199B & CIP & 4 & 4 & $2(2.0)$ & $2(2.0)$ & 4 & $0.5(8.0)$ \\
\hline XU212 & TET & 32 & 32 & $12(2.7)$ & 32 & 32 & $16(2.0)$ \\
\hline RN4220 & ERY & 256 & 256 & 256 & $32(8.0)$ & 256 & 256 \\
\hline \multirow{3}{*}{ MRSA MJMC001 } & CIP & $>32$ & $>32$ & $>32$ & $>32$ & $>32$ & $>32$ \\
\hline & TET & 0.38 & 0.38 & 0.38 & 0.38 & 0.38 & $0.19(2.0)$ \\
\hline & ERY & 96 & 96 & 96 & 96 & 96 & 96 \\
\hline \multirow[t]{3}{*}{ MRSA MJMC002 } & CIP & $>32$ & $>32$ & $>32$ & $>32$ & $>32$ & $>32$ \\
\hline & TET & 0.38 & 0.38 & $0.19(2.0)$ & 0.38 & 0.38 & $0.19(2.0)$ \\
\hline & ERY & 96 & 96 & 96 & 96 & 96 & 96 \\
\hline \multirow[t]{3}{*}{ MRSA MJMC004 } & CIP & $>32$ & $>32$ & $>32$ & $>32$ & $>32$ & $>32$ \\
\hline & TET & 0.38 & 0.38 & 0.38 & 0.38 & 0.38 & 0.38 \\
\hline & ERY & 96 & 96 & 96 & 96 & 96 & 96 \\
\hline \multirow[t]{3}{*}{ MSSA MJMC003 } & CIP & 0.19 & 0.19 & $0.094(2.0)$ & $0.094(2.0)$ & 0.19 & $0.094(2.0)$ \\
\hline & TET & 0.38 & 0.38 & 0.38 & 0.38 & 0.38 & $0.19(2.0)$ \\
\hline & ERY & 0.19 & 0.19 & $0.094(2.0)$ & $0.047(4.0)$ & 0.19 & 0.19 \\
\hline \multirow[t]{3}{*}{ MSSA MJMC009 } & CIP & 0.19 & 0.19 & $0.094(2.0)$ & $0.094(2.0)$ & 0.19 & $0.094(2.0)$ \\
\hline & TET & 0.25 & 0.25 & 0.25 & 0.25 & 0.25 & 0.25 \\
\hline & ERY & 2 & 2 & $1(2.0)$ & $0.5(4.0)$ & 2 & 2 \\
\hline \multirow[t]{3}{*}{ MSSA MJMC010 } & CIP & 0.19 & 0.19 & $0.047(4.0)$ & $0.064(3.0)$ & 0.19 & 0.19 \\
\hline & TET & 0.38 & 0.38 & $0.064(6.0)$ & 0.38 & 0.38 & $0.25(1.5)$ \\
\hline & ERY & 0.25 & 0.25 & $0.125(2.0)$ & $0.064(3.9)$ & 0.25 & $0.064(3.9)$ \\
\hline
\end{tabular}

MICs ranged between 2-fold dilutions and the highest value was chosen ( $n \geq 3$ ).CAF, PYR, THEO: $500 \mathrm{mg} / \mathrm{L}$; RES, QUIN: $100 \mathrm{mg} / \mathrm{L}$. Fold reductions are given in parentheses. 
Table 4

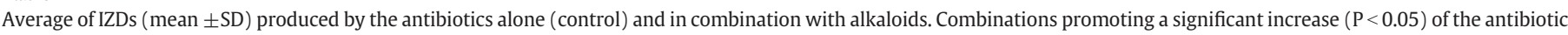
IZD are in bold.

\begin{tabular}{|c|c|c|c|c|c|c|c|}
\hline \multicolumn{8}{|l|}{ IZD (mm) } \\
\hline Isolates & Antib. & Control & CAF & RES & PYR & THEO & QUIN \\
\hline \multirow[t]{5}{*}{ СЕСТ 976} & CIP & $33.3 \pm 0.6$ & $32.0 \pm 0.0$ & $33.3 \pm 0.6$ & $32.7 \pm 1.3$ & $33.8 \pm 1.0$ & $32.7 \pm 0.5$ \\
\hline & TET & $23.7 \pm 0.6$ & $23.7 \pm 0.6$ & $24.3 \pm 0.5$ & $23.0 \pm 0.0$ & $23.3 \pm 0.6$ & $24.0 \pm 1.0$ \\
\hline & ERY & $26.3 \pm 0.6$ & $26.0 \pm 1.0$ & $27.3 \pm 0.6$ & $33.0 \pm 0.7$ & $27.3 \pm 1.2$ & $27.3 \pm 0.6$ \\
\hline & AMP & $36.0 \pm 1.0$ & $37.7 \pm 0.6$ & $45.7 \pm 0.6$ & $35.7 \pm 0.6$ & $36.7 \pm 1.3$ & $42.0 \pm 1.0$ \\
\hline & OXA & $39.7 \pm 0.6$ & $40.7 \pm 0.6$ & $38.3 \pm 0.5$ & $38.7 \pm 0.6$ & $39.7 \pm 0.6$ & $40.7 \pm 0.6$ \\
\hline SA1199B & CIP & $13.0 \pm 0.0$ & $13.0 \pm 1.0$ & $18.0 \pm 0.0$ & $17.3 \pm \mathbf{0 . 6}$ & $12.3 \pm 0.6$ & $25.0 \pm 1.0$ \\
\hline XU212 & TET & $9.0 \pm 0.0$ & $9.7 \pm 0.6$ & $13.0 \pm 0.0$ & $9.0 \pm 0.0$ & $10.0 \pm 1.0$ & $10.7 \pm 0.6$ \\
\hline RN4220 & ERY & $\mathrm{x}$ & $\mathrm{x}$ & $\mathrm{x}$ & $8.7 \pm \mathbf{0 . 6}$ & $\mathrm{x}$ & $\mathrm{x}$ \\
\hline \multirow[t]{5}{*}{ MRSA MJMC001 } & CIP & $\mathrm{x}$ & $\mathrm{x}$ & $\mathrm{x}$ & $\mathrm{x}$ & $\mathrm{x}$ & $\mathrm{x}$ \\
\hline & TET & $26.0 \pm 0.0$ & $26.7 \pm 1.3$ & $\mathbf{3 0 . 0} \pm \mathbf{0 . 0}$ & $26.3 \pm 0.5$ & $27.0 \pm 1.0$ & $30.7 \pm \mathbf{0 . 6}$ \\
\hline & ERY & $12.7 \pm 0.5$ & $12.0 \pm 0.0$ & $12.0 \pm 0.0$ & $12.0 \pm 0.0$ & $12.0 \pm 0.0$ & $12.0 \pm 0.0$ \\
\hline & AMP & $\mathrm{x}$ & $\mathrm{x}$ & $\mathrm{x}$ & $\mathrm{x}$ & $\mathrm{x}$ & $\mathrm{x}$ \\
\hline & OXA & $\mathrm{x}$ & $\mathrm{x}$ & $\mathrm{x}$ & $\mathrm{x}$ & $\mathrm{x}$ & $\mathrm{x}$ \\
\hline \multirow[t]{5}{*}{ MRSA MJMC002 } & CIP & $\mathrm{x}$ & $\mathrm{x}$ & $\mathrm{x}$ & $\mathrm{x}$ & $\mathrm{x}$ & $\mathrm{x}$ \\
\hline & TET & $26.0 \pm 0.0$ & $26.0 \pm 0.0$ & $28.0 \pm 0.0$ & $26.0 \pm 0.0$ & $26.8 \pm 1.0$ & $28.0 \pm 0.0$ \\
\hline & ERY & $12.0 \pm 0.0$ & $12.0 \pm 0.0$ & $12.0 \pm 0.0$ & $12.0 \pm 0.0$ & $12.1 \pm 0.6$ & $12.0 \pm 0.7$ \\
\hline & AMP & $\mathrm{x}$ & $\mathrm{x}$ & $\mathrm{x}$ & $\mathrm{x}$ & $\mathrm{x}$ & $\mathrm{x}$ \\
\hline & OXA & $\mathrm{x}$ & $\mathrm{x}$ & $\mathrm{x}$ & $\mathrm{x}$ & $\mathrm{x}$ & $\mathrm{x}$ \\
\hline \multirow[t]{5}{*}{ MRSA MJMC004 } & CIP & $\mathrm{x}$ & $\mathrm{x}$ & $\mathrm{x}$ & $\mathrm{x}$ & $\mathrm{x}$ & $\mathrm{x}$ \\
\hline & TET & $27.0 \pm 1.0$ & $26.7 \pm 0.6$ & $28.0 \pm 0.0$ & $27.0 \pm 0.0$ & $27.1 \pm 0.6$ & $29.7 \pm 0.5$ \\
\hline & ERY & $12.0 \pm 0.0$ & $12.0 \pm 0.0$ & $12.0 \pm 0.0$ & $12.0 \pm 0.0$ & $12.0 \pm 0.0$ & $12.0 \pm 0.0$ \\
\hline & AMP & $\mathrm{x}$ & $\mathrm{x}$ & $\mathrm{x}$ & $\mathrm{x}$ & $\mathrm{x}$ & $\mathrm{x}$ \\
\hline & OXA & $\mathrm{x}$ & $\mathrm{x}$ & $\mathrm{x}$ & $\mathrm{x}$ & $\mathrm{x}$ & $\mathrm{x}$ \\
\hline \multirow[t]{5}{*}{ MSSA MJMC003 } & CIP & $36.0 \pm 0.0$ & $36.0 \pm 0.6$ & $37.0 \pm 1.0$ & $40.0 \pm 0.0$ & $36.4 \pm 1.1$ & $38.0 \pm 1.0$ \\
\hline & TET & $35.0 \pm 0.6$ & $35.1 \pm 0.6$ & $35.0 \pm 0.7$ & $41.0 \pm 0.0$ & $35.0 \pm 0.0$ & $37.0 \pm 0.0$ \\
\hline & ERY & $31.0 \pm 1.0$ & $31.0 \pm 0.0$ & $33.0 \pm 1.0$ & $43.0 \pm \mathbf{0 . 0}$ & $31.0 \pm 1.0$ & $32.0 \pm 1.0$ \\
\hline & AMP & $14.0 \pm 1.0$ & $14.0 \pm 0.0$ & $14.3 \pm 0.6$ & $13.3 \pm 0.5$ & $14.0 \pm 1.0$ & $15.7 \pm 0.5$ \\
\hline & OXA & $21.0 \pm 0.0$ & $22.0 \pm 0.0$ & $24.0 \pm 0.0$ & $21.5 \pm 0.6$ & $22.0 \pm 0.0$ & $23.0 \pm 1.0$ \\
\hline \multirow[t]{5}{*}{ MSSA MJMC009 } & CIP & $30.0 \pm 1.0$ & $30.0 \pm 0.7$ & $38.7 \pm 0.6$ & $38.0 \pm \mathbf{0 . 0}$ & $30.3 \pm 0.6$ & $40.0 \pm 1.0$ \\
\hline & TET & $30.0 \pm 0.0$ & $30.0 \pm 0.0$ & $\mathbf{3 5 . 0} \pm \mathbf{0 . 0}$ & $35.0 \pm \mathbf{0 . 0}$ & $30.1 \pm 0.6$ & $35.0 \pm \mathbf{0 . 0}$ \\
\hline & ERY & $27.0 \pm 0.7$ & $27.8 \pm 1.0$ & $\mathbf{3 6 . 0} \pm \mathbf{0 . 0}$ & $35.3 \pm 0.6$ & $27.0 \pm 0.0$ & $32.0 \pm 0.0$ \\
\hline & AMP & $15.0 \pm 0.0$ & $16.0 \pm 0.0$ & $15.0 \pm 0.0$ & $14.3 \pm 0.6$ & $15.4 \pm 1.1$ & $16.0 \pm 0.0$ \\
\hline & OXA & $22.3 \pm 0.6$ & $22.0 \pm 1.0$ & $23.7 \pm 0.6$ & $23.0 \pm 1.0$ & $23.0 \pm 0.0$ & $22.0 \pm 0.0$ \\
\hline \multirow[t]{5}{*}{ MSSA MJMC010 } & CIP & $34.7 \pm 0.0$ & $35.4 \pm 1.1$ & $40.7 \pm 0.6$ & $40.7 \pm 0.6$ & $35.1 \pm 0.6$ & $37.7 \pm 0.6$ \\
\hline & TET & $37.0 \pm 0.0$ & $37.0 \pm 0.0$ & $39.0 \pm 0.6$ & $37.0 \pm 0.0$ & $37.0 \pm 0.0$ & $40.0 \pm 1.0$ \\
\hline & ERY & $31.0 \pm 0.0$ & $31.3 \pm 0.5$ & $40.0 \pm \mathbf{0 . 0}$ & $33.0 \pm 0.7$ & $31.3 \pm 0.5$ & $35.0 \pm 1.0$ \\
\hline & AMP & $14.0 \pm 0.0$ & $14.0 \pm 0.0$ & $13.8 \pm 1.0$ & $13.5 \pm 1.0$ & $14.0 \pm 1.0$ & $15.5 \pm 0.6$ \\
\hline & OXA & $23.3 \pm 0.6$ & $23.0 \pm 0.0$ & $23.3 \pm 0.5$ & $25.0 \pm 0.0$ & $24.0 \pm 1.0$ & $24.0 \pm 0.7$ \\
\hline
\end{tabular}

CAF, PYR, THEO: $500 \mathrm{mg} / \mathrm{L}$; RES, QUIN: $100 \mathrm{mg} / \mathrm{L} . \mathrm{x}=$ no inhibition zone.

$\mathrm{CFU} / \mathrm{mL}$, respectively, comparing with that promoted by TET alone. No effect was observed with the addition of alkaloids to ERY against S. aureus RN4220 $(P>0.05)$.

Results from each test were classified based on the interpretation of an interaction as negative/indifferent/additive/potentiation and compared between each other. Table 5 presents this comparison only for the combinations that resulted in an additive or a potentiation interaction for, at least, 1 method. Time-kill assay results showed $66.7 \%$ of agreement when compared with the other methods for SA1199B, XU212, RN4220 (indeed, this method disagrees with the others in 5 of the 6 cases as shown in Table 5 with these strains). Agreement between checkerboard, Etest, and DDM was obtained in 93 of 120 combinatorial cases (77.5\%), minor disagreements in 23 of 120 cases (19.2\%), and major disagreements were found in only 6 of 120 combinations (5.0\%). About 106 of 120 cases (87.4\%) showed agreement between checkerboard and Etest, 164 of 190 cases (86.3\%) between checkerboard and DDM, and 99 of 120 cases $(82.5 \%)$ demonstrated agreement between Etest and DDM. Indifference was most common among all three methods, being found in 157 of 190 combinations (82.6\%), considering the cases showing agreement or minor disagreement. Additive interactions were found in 14 of 190 combinations (7.4\%). Potentiating activities were only found in 11 of 190 combinations (5.8\%), also considering both the agreement and minor disagreement cases. No negative interactions were detected.

Potentiation was observed with: RES (at $100 \mathrm{mg} / \mathrm{L}$ ) when combined with TET against XU212 and MSSA10 and with CIP against
MSSA10; PYR (at $500 \mathrm{mg} / \mathrm{L}$ ) when combined with ERY against strains CECT976, RN422, and MSSA3 and 9 and with CIP against strains MSSA9 and 10; and QUIN (at $100 \mathrm{mg} / \mathrm{L}$ ) when combined with CIP against SA1199B and MSSA9. Additive interactions were obtained with: RES combined with CIP against SA1199B, MSSA3, and 9, with TET against MRSA2, and with ERY against MSSA3; PYR combined with CIP against SA1199B and MSSA3, and with TET against MSSA9; and QUIN combined with TET against MRSA1 and 2 and MSSA3, with CIP against MSSA3, and with ERY against MSSA9 and 10. No effect was observed with the combination between the $\beta$-lactams and alkaloids. Also, CAF and THEO did not potentiate any antibiotic against any strain.

To assess the suitability of the tested alkaloids for antimicrobial therapy, cytotoxicity tests were carried out by MTS tests with L929 cells. The positive growth control produced large amounts of a brown formazan product after incubation, which is an indicator of normal metabolism and that cells were able to metabolize MTS. The DMSO control presented a similar viability to the growth control $(P<0.05)$ indicating that this compound (at $2 \%(\mathrm{v} / \mathrm{v})$ ) was not toxic for the cells (data not shown). From the dose-response curves obtained, $\mathrm{IC}_{50}$ values were calculated by probit analysis (Table 6). QUIN demonstrates a high toxicity to mammalian cells, being the most toxic alkaloid ( IC $_{50}=25 \pm 2.2 \mathrm{mg} / \mathrm{L}$ ). The concentration of RES used in the antimicrobial assays, $100 \mathrm{mg} / \mathrm{L}$, was inferior to its $\mathrm{IC}_{50}(627 \pm 57 \mathrm{mg} / \mathrm{L})$. The other alkaloids were used at concentrations above their $\mathrm{IC}_{50}$, which was $352 \pm 28 \mathrm{mg} / \mathrm{L}, 274 \pm 18 \mathrm{mg} / \mathrm{L}$, and $100 \pm 4.7 \mathrm{mg} / \mathrm{L}$ for CAF, PYR, and THEO, respectively. 

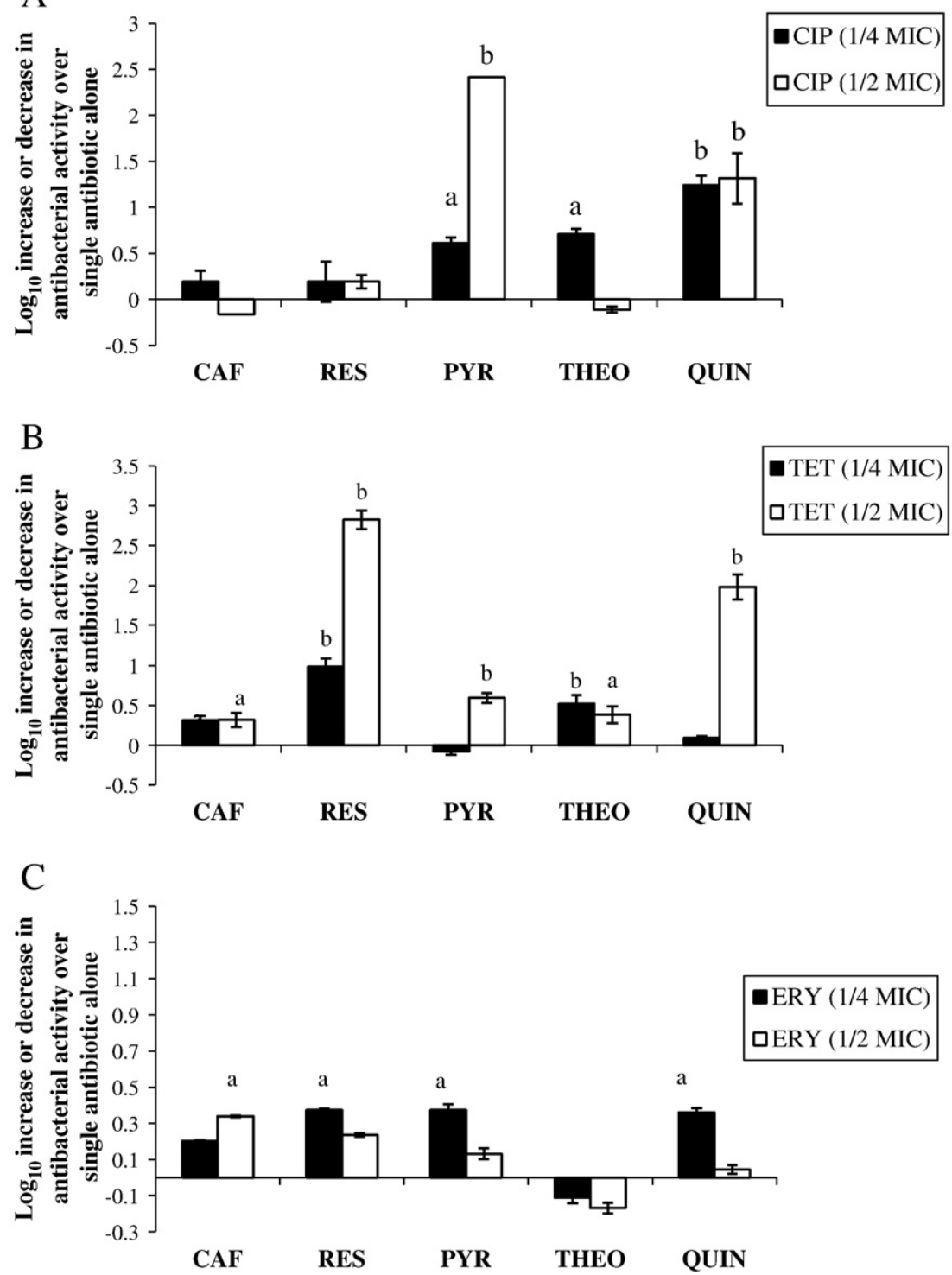

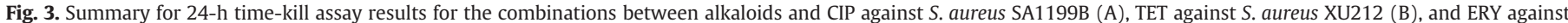
S. aureus RN4220 (C). Bars with (a) and (b) are statistically different from the antibiotic controls $(P<0.05$ and $P<0.01$, respectively).

\section{Discussion}

There are several evidences of non-antimicrobial molecules that enhanced the activity of antimicrobial agents (Abreu et al., 2012b). The combination of bioactive compounds is expected to exert a synergistic outcome or to reduce possible adverse side effects. Also, the development of active compounds in conjugation with existing antibiotics could probably avoid the emergence of resistant variants that might otherwise arise during treatment (Gibbons et al., 2003; Olajuyigbe and Afolayan, 2012). Typically, synergy indicates that the compounds in the mixture act via different mechanisms and/or targets (Lila and Raskin, 2005). Yet, the combined bioactivity of the mixture can also be potentiated when the interaction results in improved solubility, absorption, safety, stability, or bioavailability of the active principle or a resistance-modifying effect. But is synergism a valid way to think about agents with no antimicrobial activity that potentiates antibiotics? Perhaps not, in which case, it would be better to only consider this as a potentiation.

For detecting RMAs or antibiotic coadjuvants, it is expected to observe a high inactivation of resistant bacteria when the combina- tion of antibiotic/plant compound is applied and only minor or no antibacterial activity of the phytochemical. In this study, with exception of QUIN against S. aureus CECT 976, no alkaloid had antimicrobial activity. The antibiotic MICs varied depending on the methodology. The overall agreement between broth and Etest MICs was $66.7 \%$, which is due to broth MICs higher than Etest MICs. So, these results demonstrate an apparent increased sensitivity of the agar testing method over the microdilution assay. In the majority of studies, the agreement between the MICs of these 2 methods varies since these test systems measure different interactions between an antimicrobial agent and a microorganism (Mayrhofer et al., 2008; Serrano et al., 2003; Szekely et al., 1999; van der Heijden et al., 2007). Therefore, it is expected that there will be some minor differences between the systems (Rennie et al., 2012). Despite the minimal antimicrobial activity observed, several MIC reductions were obtained with RES, PYR, or QUIN combined with CIP, TET, or ERY. Of all 190 combinations performed in this study, only $5.8 \%$ and $7.4 \%$ were cases of potentiation and of additive interaction, respectively, while the remaining was considered indifferent. No potentiating activity was obtained against MRSA strains; only additive effects were observed 
Table 5

Combinatorial results obtained by checkerboard, Etest, DDM, and time-kill methods with the combination between antibiotics and alkaloids. Potentiation results are in bold.

\begin{tabular}{|c|c|c|c|c|c|c|}
\hline Isolates & Antib. & Alkal. & Checkerboard & Etest & DDM & Time-kill \\
\hline \multirow[t]{3}{*}{ СЕСТ 976} & ERY & PYR & $4.0(P)$ & $4.0(P)$ & $6.7(P)$ & \\
\hline & AMP & RES & $\mathrm{NC}(\mathrm{I})$ & n.p. & $9.7(\mathrm{P})$ & \\
\hline & & QUIN & NC (I) & n.p. & $6.0(\mathrm{P})$ & \\
\hline \multirow[t]{3}{*}{ SA1199B } & CIP & RES & $2.0(\mathrm{~A})$ & $2.0(\mathrm{~A})$ & $5.0(\mathrm{~A})$ & $0.2(\mathrm{I})$ \\
\hline & & PYR & $2.0(\mathrm{~A})$ & $2.0(\mathrm{~A})$ & $4.3(\mathrm{~A})$ & $2.4(\mathrm{P})$ \\
\hline & & QUIN & $1.3(\mathrm{I})$ & $8.0(P)$ & $12.0(P)$ & $1.3(\mathrm{~A})$ \\
\hline \multirow[t]{2}{*}{ XU212 } & TET & RES & $4.0(P)$ & $2.7(\mathbf{P})$ & $3.0(\mathrm{I})$ & $2.8(\mathrm{P})$ \\
\hline & & QUIN & $1.3(\mathrm{I})$ & $2.0(\mathrm{~A} / \mathrm{I})$ & $1.4(\mathrm{I})$ & $2.0(P)$ \\
\hline RN4220 & ERY & PYR & $4.0(P)$ & $8.0(P)$ & $8.7(P)$ & $0.4(\mathrm{I})$ \\
\hline MRSA MJMC001 & TET & QUIN & $2.0(\mathrm{~A})$ & $2.0(\mathrm{~A})$ & $4.7(\mathrm{~A})$ & \\
\hline \multirow[t]{2}{*}{ MRSA MJMC002 } & TET & RES & $2.0(\mathrm{~A})$ & $2.0(\mathrm{~A})$ & $2.0(\mathrm{I})$ & \\
\hline & & QUIN & $2.0(\mathrm{~A})$ & $2.0(\mathrm{~A})$ & $2.0(\mathrm{I})$ & \\
\hline \multirow[t]{9}{*}{ MSSA MJMC003 } & CIP & RES & $2.0(\mathrm{~A})$ & $2.0(\mathrm{~A})$ & $1.0(\mathrm{I})$ & \\
\hline & & PYR & $2.0(\mathrm{~A})$ & $2.0(\mathrm{~A})$ & $4.0(\mathrm{~A})$ & \\
\hline & & QUIN & $2.0(\mathrm{~A})$ & $2.0(\mathrm{~A})$ & $2.0(\mathrm{I})$ & \\
\hline & TET & PYR & $2.0(\mathrm{~A} / \mathrm{I})$ & $\mathrm{NC}(\mathrm{I})$ & $6.0(\mathrm{P})$ & \\
\hline & & QUIN & $2.0(\mathrm{~A})$ & $2.0(\mathrm{~A})$ & $2.0(\mathrm{I})$ & \\
\hline & ERY & RES & $2.0(\mathrm{~A})$ & $2.0(\mathrm{~A})$ & $2.0(\mathrm{I})$ & \\
\hline & & PYR & $4.0(P)$ & $4.0(P)$ & $12.0(P)$ & \\
\hline & & QUIN & $2.0(\mathrm{~A} / \mathrm{I})$ & $\mathrm{NC}(\mathrm{I})$ & NC (I) & \\
\hline & AMP & RES & $6.8(\mathrm{P})$ & $\mathrm{NC}(\mathrm{I})$ & $0.3(\mathrm{I})$ & \\
\hline \multirow[t]{12}{*}{ MSSA MJMC009 } & CIP & RES & $2.0(\mathrm{~A})$ & $2.0(\mathrm{~A})$ & $8.7(\mathrm{P})$ & \\
\hline & & PYR & $8.0(P)$ & $2.0(\mathrm{~A} / \mathrm{I})$ & $8.0(P)$ & \\
\hline & & QUIN & $4.0(P)$ & $2.0(\mathrm{~A} / \mathrm{I})$ & $10.0(P)$ & \\
\hline & TET & RES & $8.3(\mathrm{P})$ & NC (I) & $5.0(\mathrm{~A} / \mathrm{I})$ & \\
\hline & & PYR & $2.0(\mathrm{~A})$ & $\mathrm{NC}(\mathrm{I})$ & $5.0(A)$ & \\
\hline & & QUIN & $8.3(\mathrm{P})$ & NC (I) & $5.0(\mathrm{~A} / \mathrm{I})$ & \\
\hline & ERY & RES & NC (I) & $2.0(\mathrm{~A} / \mathrm{I})$ & $9.0(\mathrm{P})$ & \\
\hline & & PYR & $2.0(\mathrm{~A} / \mathrm{I})$ & $4.0(P)$ & $8.3(P)$ & \\
\hline & & QUIN & $2.0(\mathrm{~A})$ & $\mathrm{NC}(\mathrm{I})$ & $5.0(\mathrm{~A})$ & \\
\hline & AMP & RES & $6.7(\mathrm{P})$ & $\mathrm{NC}(\mathrm{I})$ & $\mathrm{NC}(\mathrm{I})$ & \\
\hline & & PYR & $13.5(\mathrm{P})$ & $\mathrm{NC}(\mathrm{I})$ & $-0.7(\mathrm{I})$ & \\
\hline & & QUIN & $6.7(\mathrm{P})$ & $\mathrm{NC}(\mathrm{I})$ & $1.0(\mathrm{I})$ & \\
\hline \multirow[t]{7}{*}{ MSSA MJMC010 } & CIP & RES & $7.7(\mathbf{P})$ & $4.0(P)$ & $6.0(P)$ & \\
\hline & & PYR & $4.0(P)$ & $3.0(P)$ & $6.0(P)$ & \\
\hline & TET & RES & $8.3(\mathrm{P})$ & $6.0(P)$ & $3.0(\mathrm{I})$ & \\
\hline & & QUIN & $8.3(\mathrm{P})$ & $1.5(\mathrm{~A} / \mathrm{I})$ & $\mathrm{NC}(\mathrm{I})$ & \\
\hline & ERY & RES & NC (I) & $2.9(\mathrm{~A} / \mathrm{I})$ & $9.0(\mathrm{P})$ & \\
\hline & & PYR & $2.0(\mathrm{~A} / \mathrm{I})$ & $3.9(\mathrm{P})$ & $2.0(\mathrm{I})$ & \\
\hline & & QUIN & $2.0(\mathrm{~A})$ & $3.9(\mathrm{P})$ & $4.0(\mathrm{~A})$ & \\
\hline
\end{tabular}

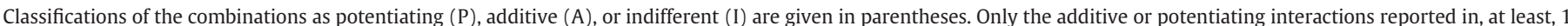

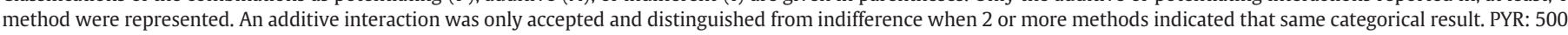
mg/L; RES, QUIN: $100 \mathrm{mg} / \mathrm{L}$. n.p. = not performed; NC = no change.

between TET and QUIN (against MRSA1 and MRSA2) and RES (against MRSA2). In fact, studies suggest that resistant bacteria are persistent in nature due to the stability of the resistance genes and transfer elements (Marquez, 2005). Concerning strains SA1199B, XU212, and RN4220, potentiation was obtained between CIP-QUIN, TET-RES, and ERY-PYR, respectively.

RES, originally extracted from Rauwolfia serpentina, was already studied by several authors due to its properties as EPI (Aeschlimann et al., 1999; Gibbons and Udo, 2000; Markham et al., 1999; Schmitz et al., 1998). In this work, this alkaloid showed a potentiating activity when combined with TET against XU212 and MSSA10 and with CIP against MRSA2. Also, additive effects were observed with RES and these antibiotics against other strains. This fact supports in general previous studies (Gibbons and Udo, 2000; Gibbons et al., 2003;

\section{Table 6}

In vitro cytotoxicity of the alkaloids ( $\mathrm{IC}_{50}$ values, $\mathrm{mg} / \mathrm{L}$ ) obtained with MTS reduction of L929 cells (mean \pm SD; $n \geq 3$ ).

\begin{tabular}{lc}
\hline Alkaloids & $\mathrm{IC}_{50}(\mathrm{mg} / \mathrm{L})$ \\
\hline CAF & $352 \pm 28$ \\
RES & $627 \pm 57$ \\
PYR & $274 \pm 18$ \\
THEO & $100 \pm 4.7$ \\
QUIN & $25.3 \pm 2.2$ \\
\hline
\end{tabular}

Schmitz et al., 1998). However, only a 2-fold reduction of MIC was observed between RES and CIP against SA1199B. RES appears to be involved especially in the inhibition of NorA and also TetK efflux pumps, but other efflux pumps may probably be implicated. While RES had effect on some $S$. aureus strains, for others, no effect was observed. This can be associated to the fact that strains could vary in the extent to which RES is able to block NorA or TetK or, also, due to the varying rates of transcription of the nor and tetK genes or differences in the stability of its messenger RNA (Schmitz et al., 1998). RES was applied at concentrations lower than its $\mathrm{IC}_{50}$, which shows that RES can be a good candidate to be used as cotherapeutic agent. The interest on this agent increases when one compares it cytotoxicity value with those of reference alkaloids used currently for chemotherapy. Abe et al. (2000) found that the growth of L929 cells was inhibited by vincristine, in a dose-dependent manner, by $20 \%$ at $0.25 \mathrm{mg} / \mathrm{L}$ and by $35 \%$ at $2.5 \mathrm{mg} / \mathrm{L}$. Rassouli et al. (2011) determined the $\mathrm{IC}_{50}$ value of vincristine $(50 \mathrm{mg} / \mathrm{L})$ and of vinblastine $(80 \mathrm{mg} / \mathrm{L})$ using 5637 cells. The $\mathrm{IC}_{50}$ values of vincristine ranged from 0.4 to 5 $\mathrm{mg} / \mathrm{L}$ when applied to varied cell lines (Chen et al., 2006).

Pyrrolidine, found naturally in the leaves of tobacco and carrot, potentiated the activity of ERY against $S$. aureus RN4220, S. aureus CECT 976, and MSSA3 and of CIP against strains MSSA9 and 10. To our knowledge, this compound has never been studied for its synergistic activity. Further tests regarding its structure-activity relationship would be necessary in order to conclude about the reason behind the 
promising results obtained with this compound. However, the toxicity results with this compound at $500 \mathrm{mg} / \mathrm{L}$ may be an obstacle to its chemotherapeutic use. It would be necessary to evaluate the pros and negative effects of this compound.

QUIN occurs naturally in the bark of Cinchona tree, and it is a wellknown compound with a long history of use due to their efficacy as an anti-malaria agent. Despite major toxicity concerns and adverse reactions among patients, QUIN remains one of the most commonly used antimalarial for therapy (van Vuuren and Viljoen, 2011). Moreover, this alkaloid was reported for the inhibition of the invasive ability of some bacteria, namely, staphylococci, which would protect the immunocompromised patients of being infected during the antimalarial treatment (Wolf et al., 2002; 2006). In this study, QUIN potentiated CIP against SA1199B and MSSA9. Several additive combinations were also observed with QUIN combined with TET and ERY.

MSSA strains and, less extensively, SA1199B, XU212, and RN4220 strains showed to be much more amenable to potentiation with the alkaloids than the MRSA strains. With the aim of finding new therapy options in mind, this is not the kind of result one would hope to see. However, given the high virulence, persistence, and resistance profile of MRSA, this was expected.

In this study, 4 distinct methods were used to evaluate the potentiating activity of alkaloids when combined with common antibiotics. It is not new that experimentation on drug interactions can lead to opposite conclusions by different methodologies. The various tests used measure quite distinct effects of antibiotic interactions against bacteria and use different endpoints (inhibition or killing) and medium state (broth versus agar) (Bonapace et al., 2000; Eliopoulos and Eliopoulos, 1988; White et al., 1996). However, with this strategy, it was obtained a good agreement between checkerboard, Etest, and DDM (77.5\%). Also, the agreements of $87.4 \%$ between checkerboard and Etest, $86.3 \%$ between checkerboard and DDM, and $82.5 \%$ between Etest and DDM were also very good. On the contrary, the agreement of time-kill assay with the other 3 methods was low. In general, the agreements obtained in the literature are diverse (Bonapace et al., 2000; Cantón et al., 2005; Lewis et al., 2002; Martin, 2010; Orhan et al., 2005; White et al., 1996). However, a variety of investigators found disagreement between checkerboard and time-kill results (Cappelletty and Rybak, 1996; Chang et al., 2007; Visalli et al., 1988; White et al., 1996).

Regarding the performance of all methods, Etest represents, apparently, the ideal testing methodology for the clinical microbiology laboratory since it is a simple and fast method with excellent reproducibility. However, it is somewhat expensive. DDM seems to be as an excellent strategy because it is also very easy to perform, it has good agreement results with the others methods, and it is much less expensive. Time-kill and checkerboard methods, despite being the most widely accepted, have many disadvantages. Time-kill assay is very laborious if a high number of combinations are required, and the results are greatly influenced by differences on the inoculum size and on the interpretation of the results (because relatively few antibiotic concentrations are examined) (White et al., 1996). Also, methods for the interpretation of kill-kinetic studies vary, and synergy has been defined by some authors as at least a 100 -fold increase in killing at $24 \mathrm{~h}$ (Bonapace et al., 2000; Jung et al., 2004; Kiraz et al., 2009; Mayer and Nagy, 1999), while other authors consider a 200-fold increase (Guo et al., 2008; Leonard, 2012; Tan et al., 2011). Relatively to checkerboard, the endpoint (i.e., the complete inhibition of growth) is a qualitative measure (Tariq et al., 1995), and the occurrence of synergy appears to be highly dependent on the method of interpretation (Bonapace et al., 2002). Also, the reproducibility of checkerboard is hardly the best.

In conclusion, in this study, several plant alkaloids were tested in combination with common antibiotics in order to find potentiating antimicrobial activities. The use of 4 methods to characterize the activity of the combinations was advantageous since it allowed to compare the efficacy of each method and to obtain more guarantees about the certainty of the potentiating combinations obtained. DDM had good correlation with the other methods, and it is a low-price, easy, and fast way of determining synergism between the compounds. Two compounds were especially highlighted as antibiotic coadjuvants: RES and PYR. QUIN would be a viable option if not for the high toxicity of this compound. RES is already known as an EPI for the NorA and TetK efflux pumps. This study supports the results already obtained by other authors. Furthermore, cytotoxicity values of RES are favorable, which is a good sign for the possible future development of cotherapies with this alkaloid in animal models and in vivo tests. Pyrrolidine showed a capacity for potentiating ERY against $S$. aureus RN4220, CECT 976, and MSSA3 and CIP against MSSA9 and 10 strains.

\section{Acknowledgments}

The authors are very grateful to Professor Simon Gibbons (Department of Pharmaceutical and Biological Chemistry, The School of Pharmacy, UCL School of Pharmacy, London) for providing some of the bacterial strains. This work was supported by Operational Programme for Competitiveness Factors - COMPETE and by FCT Portuguese Foundation for Science and Technology through Projects Bioresist - PTDC/EBB-EBI/105085/2008; Phytodisinfectants - PTDC/ DTP-SAP/1078/2012 and the PhD grants awarded to Ana Abreu (SFRH/BD/84393/2012) and Anabela Borges (SFRH/BD/63398/2009).

\section{References}

Abe S, Ochi H, Takahashi Y, Ishijima S, Osumi M, Yamaguchi H. Characteristic biological effects of itraconazole on L929 fibroblasts and their cell membrane. J Infect Chemother 2000;6:35-40.

Abreu AC, Borges A, Saavedra MJ, Simões M. Antibacterial activity of phenyl isothiocyanate on Escherichia coli and Staphylococcus aureus. Med Chem 2012a;12:756-61.

Abreu AC, McBain AJ, Simões M. Plants as sources of new antimicrobials and resistancemodifying agents. Nat Prod Rep 2012b;29:1007-21.

Aeschlimann JR, Dresser LD, Kaatz GW, Rybak MJ. Effects of NorA inhibitors on in vitro antibacterial activities and postantibiotic effects of levofloxacin, ciprofloxacin, and norfloxacin in genetically related strains of Staphylococcus aureus. Antimicrob Agents Chemother 1999;43:335-40.

Baran ET, Tuzlakoglu K, Salgado AJ, Reis RL. Multichannel mould processing of 3D structures from microporous coralline hydroxyapatite granules and chitosan support materials for guided tissue regeneration/engineering. J Mater Sci Mater Med 2004; $15: 161-5$

Bonapace CR, Bosso JA, Friedrich LV, White RL. Comparison of methods of interpretation of checkerboard synergy testing. Diagn Microbiol Infect Dis 2002;44:363-6.

Bonapace CR, White RL, Friedrich LV, Bosso JA. Evaluation of antibiotic synergy against Acinetobacter baumannii: a comparison with Etest, time-kill, and checkerboard methods. Diagn Microbiol Infect Dis 2000;38:43-50.

Cantón E, Pemán J, Gobernado M, Viudes A, Espinel-Ingroff A. Synergistic activities of fluconazole and voriconazole with terbinafine against four Candida species determined by checkerboard, time-kill, and Etest methods. Antimicrob Agents Chemother 2005;49:1593-6.

Cappelletty DM, Rybak MJ. Comparison of methodologies for synergism testing of drug combinations against resistant strains of Pseudomonas aeruginosa. Antimicrob Agents Chemother 1996;40:677-83.

Chan BCL, Ip M, Lau CBS, Lui SL, Jolivalt C, Ganem-Elbaz C, et al. Synergistic effects of baicalein with ciprofloxacin against NorA over-expressed methicillin-resistant Staphylococcus aureus (MRSA) and inhibition of MRSA pyruvate kinase. J Ethnopharmacol 2011;137:767-73.

Chang P-C, Li H-Y, Tang H-J, Liu J-W, Wang J-J, Chuang Y-C. In vitro synergy of baicalein and gentamicin against vancomycin-resistant Enterococcus. J Microbiol Immunol Infect 2007;40:56-61.

Chen Y-L, Lin S-Z, Chang J-Y, Cheng Y-L, Tsai N-M, Chen S-P, et al. In vitro and in vivo studies of a novel potential anticancer agent of isochaihulactone on human lung cancer A549 cells. Biochem Pharmacol 2006;72:308-19.

Clinical and Laboratory Standards Institute (CLSI). Performance standards for antimicrobial susceptibility testing; approved standard - sixth Edition, M7-A6. Document M100-S17. Wayne, PA: CLSI; 2003.

Cowan MM. Plant products as antimicrobial agents. Clin Microbiol Rev 1999;12: 564-82.

Eliopoulos GM, Eliopoulos CT. Antibiotic combinations: Should they be tested? Clin Microbiol Rev 1988;1:149-56.

Gibbons S. Anti-staphylococcal plant natural products. Nat Prod Rep 2004;21:263-77.

Gibbons S, Oluwatuyi M, Kaatz GW. A novel inhibitor of multidrug efflux pumps in Staphylococcus aureus. J Antimicrob Chemother 2003;51:13-7. 
Gibbons S, Udo EE. The effect of reserpine, a modulator of multidrug efflux pumps, on the in vitro activity of tetracycline against clinical isolates of methicillin-resistant Staphylococcus aureus (MRSA) possessing the Tet(K) determinant. Phytother Res 2000;14:139-40.

Guo Q, Sun S, Yu J, Li Y, Cao L. Synergistic activity of azoles with amiodarone against clinically resistant Candida albicans tested by chequerboard and time-kill methods. J Med Microbiol 2008;57:457-62.

Hemaiswarya S, Kruthiventi A, Doble M. Synergism between natural products and antibiotics against diseases. Phytomedicine 2008;15:639-52.

ISO document 10993. Biological compatibility of medical devices. 5. Test for cytotoxicity: In vitro methods. Switzerland; 1992.

Jung R, Husain M, Choi MK, Fish DN. Synergistic activities of moxifloxacin combined with piperacillin-tazobactam or cefepime against Klebsiella pneumoniae, Enterobacter cloacae, and Acinetobacter baumannii clinical isolates. Antimicrob Agents Chemother 2004;48:1055-7.

Kalan, L, Wright, GD. Antibiotic adjuvants: multicomponent anti-infective strategies. Exp Rev Mol Med 2011; 13:null-null.

Khan IA, Mirza ZM, Kumar A, Verma V, Qazi GN. Piperine, a phytochemical potentiator of ciprofloxacin against Staphylococcus aureus. Antimicrob Agents Chemother 2006;50:810-2.

Kiraz N, Daäÿ I, Yamac M, Kiremitci A, Kaåÿifoäÿlu N, Akgun Y. Antifungal activity of caspofungin in combination with amphotericin B against Candida glabrata: Comparison of disk diffusion, Etest, and time-kill methods. Antimicrob Agents Chemother 2009;53:788-90.

Lambert RJW, Johnston MD, Hanlon GW, Denyer SP. Theory of antimicrobial combinations: biocide mixtures - synergy or addition? J App Microbiol 2003;94: 747-59.

Leonard, SN. Synergy between vancomycin and nafcillin against Staphylococcus aureus in an in vitro pharmacokinetic/pharmacodynamic model. PLoS ONE2012; 7:e42103.

Lewis RE, Diekema DJ, Messer SA, Pfaller MA, Klepser ME. Comparison of Etest, chequerboard dilution and time-kill studies for the detection of synergy or antagonism between antifungal agents tested against Candida species. J Antimicrob Chemother 2002;49:345-51.

Lila MA, Raskin I. Health-related interactions of phytochemicals. J Food Sci 2005;70: 20-7.

Mackay ML, Milne K, Gould IM. Comparison of methods for assessing synergic antibiotic interactions. Int J Antimicrob Agents 2000;15:125-9.

Markham PN, Westhaus E, Klyachko K, Johnson ME, Neyfakh AA. Multiple novel inhibitors of the NorA multidrug transporter of Staphylococcus aureus. Antimicrob Agents Chemother 1999;43:2404-8.

Marquez B. Bacterial efflux systems and efflux pumps inhibitors. Biochimie 2005;87: 1137-47.

Martin, S. In vitro antimicrobial synergy testing of Acinetobacter baumannii. Unpublished Master thesis, University of Stellenbosch, 2010

Mayer I, Nagy E. Investigation of the synergic effects of aminoglycoside-fluoroquinolone and third-generation cephalosporin combinations against clinical isolates of Pseudomonas spp. J Antimicrob Chemother 1999;43:651-7.

Mayrhofer S, Domig KJ, Mair C, Zitz U, Huys G, Kneifel W. Comparison of broth microdilution, Etest, and agar disk diffusion methods for antimicrobial susceptibility testing of Lactobacillus acidophilus group members [down-pointing small open triangle]. Appl Environ Microbiol 2008;74:3745-8.

National Committee for Clinical Laboratory Standards (NCCLS/CLSI). Methods for determining bactericidal activity of antimicrobial agents. Approved Standard M26-A. Wayne, PA: NCCLS; 1999.

National Committee for Clinical Laboratory Standards (NCCLS/CLSI). Methods for dilution antimicrobial susceptibility test for bacteria that grow aerobically. Approved standard M7-A6. Wayne, PA: NCCLS; 2003.

Nicodemo AC, Araujo MRE, Ruiz AS, Gales AC. In vitro susceptibility of Stenotrophomonas maltophilia isolates: comparison of disc diffusion, Etest and agar dilution methods. J Antimicrob Chemother 2004:53:604-8.

Olajuyigbe 00, Afolayan AJ. Synergistic interactions of methanolic extract of Acacia mearnsii De Wild. with antibiotics against bacteria of clinical relevance. Int J Mol Sci 2012;13:8915-32.

Oluwatuyi M, Kaatz GW, Gibbons S. Antibacterial and resistance modifying activity of Rosmarinus officinalis. Phytochemistry 2004;65:3249-54.

Orhan G, Bayram A, Zer Y, Balci I. Synergy tests by E test and checkerboard methods of antimicrobial combinations against Brucella melitensis. J Clin Microbiol 2005;43: 140-3.
Phatthalung PN, Chusri S, Voravuthikunchai SP. Thai ethnomedicinal plants as resistant modifying agents for combating Acinetobacter baumannii infections. BMC Complement Altern Med 2012;12:1-8.

Rand $\mathrm{KH}$, Houck HJ, Brown P, Bennet D. Reproducibility of the microdilution checkerboard method for antibiotic synergy. Antimicrob Agents Chemother 1996;37:613-5.

Rassouli FB, Matin MM, Iranshahi M, Bahrami AR. Investigating the cytotoxic and apoptosis inducing effects of monoterpenoid stylosin in vitro. Fitoterapia 2011;82: 742-9.

Rennie RP, Turnbull L, Brosnikoff C, Cloke J. First comprehensive evaluation of the M.I.C. evaluator device compared to Etest and CLSI broth microdilution for MIC testing of aerobic Gram-positive and Gram-negative bacterial species. J Clin Microbiol 2012;50:1147-52.

Roccaro AS, Blanco AR, Giuliano F, Rusciano D, Enea V. Epigallocatechin-gallate enhances the activity of tetracycline in Staphylococci by inhibiting its efflux from bacterial cells. Antimicrob Agents Chemother 2004;48:1968-73.

Saavedra MJ, Borges A, Dias C, Aires A, Bennett RN, Rosa ES, et al. Antimicrobial activity of phenolics and glucosinolate hydrolysis products and their synergy with streptomycin against pathogenic bacteria. Med Chem 2010;6:174-83.

Schmitz FJ, Fluit AC, Lückefahr M, Engler B, Hofmann B, Verhoef J, et al. The effect of reserpine, an inhibitor of multidrug efflux pumps, on the in vitro activities of ciprofloxacin, sparfloxacin and moxifloxacin against clinical isolates of Staphylococcus aureus. J Antimicrob Chemother 1998;42:807-10.

Sebaugh JL. Guidelines for accurate EC50/IC50 estimation. Pharm Stat 2011;10:128-34

Serrano MC, Morilla D, Valverde A, Chávez M, Espinel-Ingroff A, Claro R, et al Comparison of Etest with modified broth microdilution method for testing susceptibility of Aspergillus spp. to voriconazole. J Clin Microbiol 2003;41:5270-2.

Simões M, Rocha R, Coimbra MA, Vieira M. Enhancement of Escherichia coli and Staphylococcus aureus antibiotic susceptibility using sesquiterpenoids. Med Chem 2008:4:616-23.

Smith E, Williamson M, Wareham N, Kaatz G, Gibbons S. Antibacterials and modulators of bacterial resistance from the immature cones of Chamaecyparis lawsoniana. Phytochemistry 2007;68:210-7.

Sopirala MM, Mangino JE, Gebreyes WA, Biller B, Bannerman T, Balada-Llasat J-M, et al. Synergy testing by Etest, microdilution checkerboard, and time-kill methods for pan-drug-resistant Acinetobacter baumannii. Antimicrob Agents Chemother 2010;54:4678-83.

Szekely A, Johnson EM, Warnock DW. Comparison of E-Test and broth microdilution methods for antifungal drug susceptibility testing of molds. J Clin Microbiol 1999;37:1480-3.

Tan TY, Lim TP, Lee WHL, Sasikala S, Hsu LH, Kwa AL-H. In vitro antibiotic synergy in extensively drug-resistant Acinetobacter baumannii: the effect of testing by timekill, checkerboard, and Etest methods. Antimicrob Agents Chemother 2011;55 436-8.

Tariq VN, Scott EM, McCain NE. Use of decimal assay for additivity to demonstrate synergy in pair combinations of econazole, nikkomycin $Z$, and ibuprofen against Candida albicans in vitro. Antimicrob Agents Chemother 1995;39:2615-9.

van der Heijden I, Levin A, De Pedri E, Fung L, Rossi F, Duboc G, et al. Comparison of disc diffusion Etest and broth microdilution for testing susceptibility of carbapenemresistant P. aeruginosa to polymyxins. Ann Clin Microbiol Antimicrob 2007;6:8.

van Vuuren S, Viljoen A. Plant-based antimicrobial studies - methods and approaches to study the interaction between natural products. Planta Med 2011;77:1168-82.

Visalli MA, Jacobs MR, Appelbaum PC. Determination of activities of levofloxacin, alone and combined with gentamicin, ceftazidime, cefpirome, and meropenem, against 124 strains of Pseudomonas aeruginosa by checkerboard and time-kill methodology. Antimicrob Agents Chemother 1988;42:953-5.

White RL, Burgess DS, Manduru M, Bosso JA. Comparison of three different in vitro methods of detecting synergy: time-kill, checkerboard, and E test. Antimicrob Agents Chemother 1996;40:1914-8.

Wolf R, Baroni A, Greco R, Donnarumma G, Ruocco E, Tufano MA, et al. Quinine sulfate and bacterial invasion. Ann Clin Microbiol Antimicrob 2002:1:5.

Wolf R, Tufano MA, Ruocco V, Grimaldi E, Ruocco E, Donnarumma G, et al. Quinine sulfate inhibits invasion of some bacterial skin pathogens. Int J Dermatol 2006;45: 661-3.

Yam TS, Hamilton-Miller JM, Shah S. The effect of a component of tea (Camellia sinensis) on methicillin resistance, PBP2' synthesis, and beta-lactamase production in Staphylococcus aureus. J Antimicrob Chemother 1998;42:211-6.

Zimmermann GR, Lehár J, Keith CT. Multi-target therapeutics: when the whole is greater than the sum of the parts. Drug Discov Today 2007;12:34-42. 